\title{
Avaliação de solos sob diferentes períodos de aplicação com vinhaça ${ }^{1}$
}

\author{
Felizarda V. Bebée ${ }^{2}$ Mário M. Rolim ${ }^{3}$, Elvira M. R. Pedrosa ${ }^{3}$, George B. Silva ${ }^{3} \&$ Veronildo S. 0 liveira $^{3}$
}

\section{RESU MO}

0 objetivo deste estudo foi avaliar as alterações físico-químicas associadas à profundidade e respectivas correlações em solos sob diferentes períodos de fertirrigação com vinhaça. Para isto foram selecionadas na Usina Santa Tereza, PE, quatro áreas: Área 1, com 3 anos sob fertigação com vinhaça; Área 2, com 7 anos; Área 3, com 15 anos e Área 4, sem aplicação de vinhaça. Em cada uma das áreas foram marcados 20 pontos com distância de $10 \mathrm{~m}$, georreferenciados, formando uma malha e coletadas amostras de solo nas profundidades de 0-10, 10-20 e 20-40 cm. A pós a amostragem o solo foi secado ao ar, destorroado e peneirado para realização de análises granulométricas: areia, silte e argila e físicoquímicas: $\mathrm{Ca}, \mathrm{Mg}, \mathrm{K}, \mathrm{Na}$, trocável, $\mathrm{pH}$ (1:2,5 solo:água) e condutividade elétrica ( $\left.\mathrm{CE}_{\mathrm{es}}\right)$ no extrato da pasta saturada. 0 grau de correlação linear simples entre os pares de dados foi determinado pelo coeficiente de correlaçãa de Pearson. Os resultados obtidos mostraram correlação entre profundidade e demais variáveis em todas as áreas em estudo tornando evidente que a aplicação de vinhaça altera a concentração dos cátions, de acordo com as características dos solos e o manejo de cada área.

Palavras-chave: cana-de-açúcar, fertilidade do solo, aproveitamento de resíduos

\section{Evaluation of soils under different periods of stillage aplication}

\begin{abstract}
The objective of this study was to evaluate physico-chemical alterations associated to soil depth and respective correlations in soils under periods of different stillage fertigation. Therefore, four areas were selected at U sina Santa Tereza: Area 1), irrigated with stillage for 3 years; Area 2), for 7 years; Area 3), 10 years; Area 4), without stillage application. In each area 20 points were demarcated and georeferenced, forming a mesh. Soil samples were collected at depths of 0 - 10, $10-20$ and $20-40 \mathrm{~cm}$. After sampling, the soil was air dried, prepared and passed through sieves for analysis of particle size: sand, silt, clay, and for the physico-chemical properties: exchangeahle $\mathrm{Ca}, \mathrm{Mg}, \mathrm{K}, \mathrm{Na}$; $\mathrm{pH}$ (1:2.5 soil: water); and electrical conductivity of saturated paste extract. Simple linear correlation coefficients of Pearson between pairs of data were obtained. The results pointed out relation between depth and other variables in all areas, indicating stillage application alters cation concentration depending on soil characteristics and management of each area.
\end{abstract}

Key words: sugarcane, soil fertility, use of residues

1 Parte da Dissertação de Mestrado da primeira autora apresentada ao Programa de Pós-Graduação em Engenharia Agrícola, UFRPE

2 DTR/U FRPE. Rua Dom Manoel de Medeiros s/n, Dois Irmãos, CEP 52171-900, Recife, PE. Fone: (81) 3320-6276. E-mail: felizvb@yahoo.com

3 DTR/UFRPE. Fone: (81) 3320-6276. E-mail: rolim@dtr.ufrpe.br; elvira.pedrosa@dtr.ufrpe.br; silvagb@yahoo.com.br; verofat@hotmail.com.br 


\section{INTRODUÇÃO}

O Brasil é o maior produtor de cana-de-açúcar (Saccharum spp.) do mundo, seguido da Índia e Austrália. Em média, 55\% da cana produzida no Brasil se transformam em álcool e 45\% em açúcar. No País, ela cana é plantada no Centro-Sul e no Norte-Nordeste, o que permite dois períodos de safra (UNICA, 2007). Em 2006, a participação brasileira atingiu 35,4 \% do total de 48 bilhões de litros de álcool produzido no mundo, evidenciando aumento de 4,35\% em relação a 2005. Este aumento significativo na produção de álcool é reflexo do crescimento da produção de etanol nos Estados Unidos a partir do milho, da oferta brasileira de álcool, além da maior demanda por combustíveis renováveis (Brasil, 2005).

Uma das consequências do aumento da produção do álcool é a produção de grande volume de vinhaça, resíduo altamente poluente devido à presença de alta demanda bioquímica de oxigênio (DBO) e demanda química de oxigênio (DQO), consumindo de 12.000 a $20.000 \mathrm{mg}$ de oxigênio por litro de substâncias biodegradáveis (Freire \& Cortêz, 2000). Além da alta carga orgânica, a vinhaça é rica em potássio, cálcio, magnésio e sódio, com desbalanceamento do potássio em relação aos demais elementos. Uma das formas mais econômicas e eficientes de utilização da vinhaça é a disposição no solo, prática comum, considerada uma forma de tratamento e de disposição final (Feigin et al., 1991).

A fertirrigação com vinhaça é bastante difundida nas regiões canavieiras com resultados satisfatórios em relação às alterações químicas no solo, como o aumento de matéria orgânica, $\mathrm{pH}$, teores de cálcio $(\mathrm{Ca})$, magnésio $(\mathrm{Mg})$ e potássio (K) trocáveis. Quando aplicada adequadamente, cerca de $150 \mathrm{~m}^{3} \mathrm{ha}^{-1}$ de vinhaça equivale a uma adubação de $61 \mathrm{~kg} \mathrm{ha}^{-1}$ de nitrogênio, 343 kg ha-1 de K e 108 kg ha-1 de Ca (Medeiros et al., 2003).

Brito et al. (2005) verificaram que doses crescentes de vinhaça aumentam a concentração de K trocável, em especial nas camadas mais superficiais do Argissolo estudado. Semelhantemente, Camargo et al. (1983) e Sengik et al. (1988), estudando os efeitos de diferentes doses de vinhaça provenientes de mosto misto sobre dois diferentes tipos de solo, também observaram acréscimo de bases trocáveis e pH na camada superior e em profundidade, quando aplicaram a dose mais elevada.

Segundo Paula et al. (1999), os elevados teores de K no complexo sortivo do solo podem acarretar acréscimos também na solução do solo, propiciando lixiviação dos nutrientes em profundidade. A aplicação inadequada de vinhaça pode contribuir para o aumento dos elementos químicos no solo, principalmente de $\mathrm{K}$ e sódio $(\mathrm{Na})$ que influenciam o aumento da condutividade elétrica do extrato de saturação do solo (Brito et al., 2005).

De acordo com Cambuim (1983), o K apresenta comportamento mais dependente de períodos de incubação ao longo da profundidade que com doses de vinhaça. Glória (1976) constatou maiores teores de $\mathrm{K}$ em linhas de cana irrigadas com vinhaça que as sem irrigação, principalmente a partir do terceiro ano.

A partir do que foi exposto, o objetivo do presente estudo foi avaliar as alterações físico-químicas em função da pro- fundidade e respectivas correlações em solos sob diferentes períodos de fertirrigação com vinhaça.

\section{MATERIAL E MÉTODOS}

A área experimental está localizada na Usina Santa Tereza, Goiana, PE, localizada na Mesorregião Mata e Microrregião Mata Setentrional do Estado de Pernambuco, situada nas coordenadas $7^{\circ} 33$ ' 38” de latitude Sul e 3500' 09” de longitude Oeste. A partir do histórico da usina em relação à aplicação de vinhaça, foram selecionadas quatro áreas para constituírem os tratamentos e neles classificados os solos, através de abertura de trincheira com profundidade de 1,5 m em cada área experimental. Para fins de classificação as amostras foram coletadas em cada horizonte do perfil do solo, em seguida acondicionadas em sacos plásticos e, posteriormente, transportadas para o Laboratório de Mecânica dos Solos e Aproveitamento de Resíduos da UFRPE, para as análises físico-químicas.

As análises foram: granulometria pelo método do densímetro, densidade do solo (Ds) pelo método do anel volumétrico para as amostras mais argilosas e pelo método da proveta para as arenosas, capacidade campo (CC) e ponto de murcha permanente (PMP) obtidas no aparelho Extrator de Richards e a determinação da porosidade total (P) (Tabela 1). Todas as análises foram realizadas segundo metodologia da EMBRAPA (1997).

Os solos foram classificados conforme EMBRAPA (2006), como: Área 1, correspondente a um Espodossolo Ferrihumilúvico Órtico espessarênicos em que vem sendo aplicada vinhaça por um período de 3 anos; Área 2, um Espodossolo Ferrihumilúvico Órtico espessarênicos com 7 anos; Área 3, um Argissolo Amarelo Distrocoeso latossólico com 15 anos de aplicação de vinhaça; e Área 4, um Argissolo Amarelo Distrófico fragipânico que nunca recebeu aplicação de vinhaça.

Tabela 1. Caracterização física dos solos das áreas estudadas

\begin{tabular}{|c|c|c|c|c|c|c|c|}
\hline \multirow{3}{*}{$\begin{array}{l}\text { Prof. }{ }^{(2)} \\
\text { (cm) }\end{array}$} & \multicolumn{3}{|c|}{ Composição granulométrica } & \multirow{3}{*}{$\begin{array}{c}\mathrm{Ds}^{(3)} \\
\mathrm{g} \mathrm{cm^{-3 }}\end{array}$} & \multirow{3}{*}{$\begin{array}{l}P(4) \\
(\%)\end{array}$} & \multirow{3}{*}{$\begin{array}{l}\text { CC(5) } \\
(\%)\end{array}$} & \multirow{3}{*}{$\begin{array}{c}\text { PMP(6) } \\
(\%)\end{array}$} \\
\hline & Areia & Silte & Argila & & & & \\
\hline & \multicolumn{3}{|c|}{$\mathrm{g} \mathrm{kg}^{-1}$} & & & & \\
\hline \multicolumn{8}{|l|}{ Área 1} \\
\hline $0-25$ & 932 & 28 & 40 & 1,54 & 41,52 & 4,77 & 2,06 \\
\hline $25-40$ & 935 & 25 & 40 & 1,58 & 41,54 & 3,55 & 1,76 \\
\hline $40-90$ & 933 & 28 & 39 & 1,70 & 35,40 & 2,54 & 0,74 \\
\hline $90-100$ & 927 & 42 & 31 & 1,76 & 33,12 & 2,83 & 0,97 \\
\hline \multicolumn{8}{|l|}{ Área 2} \\
\hline $0-18$ & 932 & 26 & 42 & 1,52 & 39,96 & 6,99 & 2,29 \\
\hline $18-55$ & 943 & 7 & 50 & 1,55 & 44,03 & 3,19 & 1,25 \\
\hline $55-100$ & 941 & 18 & 41 & 1,69 & 39,33 & 3,57 & 1,27 \\
\hline \multicolumn{8}{|l|}{ Área 3} \\
\hline $0-15$ & 555 & 86 & 359 & 1,20 & 54,56 & 18,99 & 11,37 \\
\hline $15-32$ & 544 & 45 & 411 & 1,46 & 44,14 & 18,62 & 11,80 \\
\hline $32-65$ & 434 & 57 & 509 & 1,52 & 43,06 & 19,97 & 13,17 \\
\hline $65-100$ & 374 & 116 & 510 & 1,35 & 48,91 & 22,91 & 15,01 \\
\hline \multicolumn{8}{|l|}{ Área 4} \\
\hline $0-20$ & 818 & 53 & 129 & 1,40 & 45,67 & 5,72 & 3,58 \\
\hline $20-36$ & 773 & 48 & 179 & 1,46 & 43,16 & 5,22 & 3,27 \\
\hline $36-75$ & 713 & 29 & 258 & 1,50 & 42,25 & 4,14 & 3,04 \\
\hline $75-100$ & 674 & 48 & 278 & 1,38 & 46,57 & 4,52 & 2,88 \\
\hline
\end{tabular}

Hor $^{(1)}$ - horizonte; Prof ${ }^{(2)}$ - profundidade; $\mathrm{Ds}^{(3)}$ - densidade do solo; $\mathrm{P}^{(4)}$ - porosidade total; $\mathrm{CC}^{(5)}$ - capacidade de campo a 0,33 MPa; $\mathrm{PMP}^{(6)}-1,5 \mathrm{MPa}$ 
Os solos das áreas experimentais 1, 2 e 3 foram fertirrigados com uma média de $300 \mathrm{~m}^{3}$ de vinhaça por hectare ano.

Em cada área selecionada as amostras de solo foram retiradas em 20 pontos georreferenciados, com distâncias regulares de $10 \mathrm{~m}$ formando uma malha (Figura 1). A amostragem de solo foi realizada com a utilização de trado tipo holandês nas profundidades 0-10, 10-20 e 20-40 cm totalizando 240 amostras de solo, entre as linhas da cana-de-açúcar; após a coleta as amostras foram transportadas para o Laboratório de Mecânica dos Solos e Aproveitamento de Resíduos da UFRPE para secagem ao ar livre.

Após a secagem, as amostras foram destorroadas e peneiradas em malha de $2 \mathrm{~mm}$ (TFSA) para realização das seguintes análises: granulometria (areia, silte e argila); pH em água na proporção 1:2,5 (solo:água); Ca e Mg disponíveis extraídos em KCL 1 mol L-1; K e Na disponíveis extraídos em so- lução de Mehlich 1 e $\mathrm{CE}_{\mathrm{es}}$, todas conforme metodologia da EMBRAPA (1997).

O grau de correlação linear simples entre os pares de dados obtidos foi determinado pelo coeficiente de correlação de Pearson (r), para cada área estudada utilizando-se o programa SAS - Statistical Analitical System (SAS Institute, 1989).

\section{RESULTADOS E DISCUSSÃO}

Os teores de K trocável no solo se correlacionaram negativamente com a profundidade, independentemente da área experimental estudada, havendo redução da concentração com a profundidade (Figura 2). Nas Áreas 1 e 2 houve incremento de $\mathrm{K}$, principalmente na camada superficial, pois os valores médios nas camadas de 0-10 e 10-20 cm foram

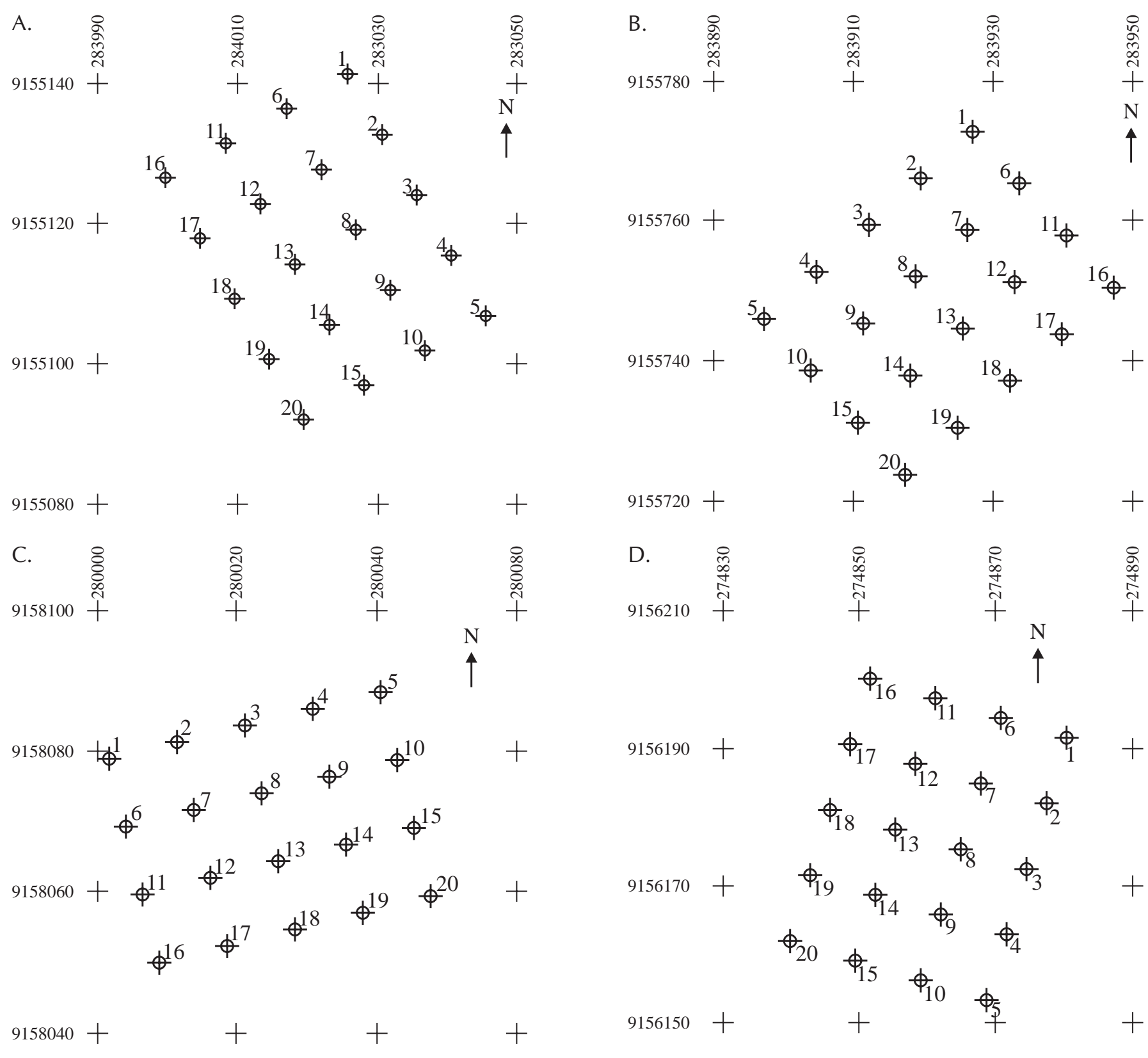

Figura 1. Localização dos pontos de amostragem da Área 1 (A), Área 2 (B), Área 3 (C) e Área 4 (D) 
superiores a de 20-40 cm. Especificamente na camada de 0-10 cm, os valores de $\mathrm{K}$ foram superiores a de $10-20 \mathrm{~cm}$ e 20-40 cm (Figura 2). A amostragem de solo nas Áreas 1 e 2 foi realizada após dois dias da aplicação de vinhaça no campo e, depois deste período, não houve registro de precipitação para que o $\mathrm{K}$ lixiviasse no perfil do solo, ficando retido sobretudo na camada superficial, maior contato entre os colóides do solo e a vinhaça; além disto, pode-se observar que as áreas fertirrigadas com vinhaça apresentaram maior teor de K em relação à área sem vinhaça. Paula et al. (1999) observaram em estudo com solos de baixo potencial produtivo, aumento de $\mathrm{K}$ nas camadas de $0-20 \mathrm{~cm}$ e de $20-40 \mathrm{~cm}$.
Ainda para o $\mathrm{K}$, pode-se verificar que os desvios padrão foram de 0,19; 0,32; 0,10 e 0,09 nas Áreas 1, 2, 3 e 4, respectivamente, na profundidade $0-10 \mathrm{~cm}$. Os resultados sugerem que a distribuição de vinhaça nessas áreas não foi uniforme, concordando com Corá et al. (2004). Essa distribuição deve ser decorrente da irrigação por aspersão efetuada, utilizando-se sistema autopropelido com canhão hidráulico, cuja uniformidade de aplicação geralmente é baixa.

Houve correlação significativa ( $\mathrm{P} £ 0,05)$ entre os teores de $\mathrm{K}$ e de $\mathrm{Ca}$, Mg e Na nas Áreas 1, 2 e 3, fertirrigadas com vinhaça, enquanto na Área 4 o K se correlacionou com o Na (Tabela 2).

Tabela 2. Coeficientes de correlação entre variáveis do solo e com a profundidade nas diversas áreas estudadas

\begin{tabular}{|c|c|c|c|c|c|c|c|c|c|}
\hline & \multicolumn{9}{|c|}{ Variáveis } \\
\hline & K & $\mathrm{Na}$ & $\mathrm{Ca}$ & Mg & CE & pH & AR & $S$ & AG \\
\hline \multicolumn{10}{|c|}{ Área 1} \\
\hline Prof & $-0,72^{\star *}$ & $-0,15 \mathrm{~ns}$ & $-0,68^{* *}$ & $-0,63^{* *}$ & $-0,84^{\star *}$ & $-0,11 \mathrm{~ns}$ & $0,43^{\star *}$ & $-0,33^{\star *}$ & $-0,50$ ** \\
\hline K & 1,00 & 0,20 * & $0,52^{\star *}$ & $0,54^{\star *}$ & $0,76^{\star *}$ & $0,27^{\star *}$ & $-0,13 \mathrm{~ns}$ & $0,09 \mathrm{~ns}$ & $0,19 \mathrm{~ns}$ \\
\hline $\mathrm{Na}$ & & 1,00 & $0,28 * *$ & 0,27 ** & $0,22 *$ & $0,12 \mathrm{~ns}$ & $0,01 \mathrm{~ns}$ & $-0,01 \mathrm{~ns}$ & $0,00 \mathrm{~ns}$ \\
\hline $\mathrm{Ca}$ & & & 1,00 & $0,78 * *$ & $0,73^{\star *}$ & $0,10 \mathrm{~ns}$ & $-0,29 * *$ & 0,31 ** & $0,04 \mathrm{~ns}$ \\
\hline $\mathrm{Mg}$ & & & & 1,00 & 0,67 ** & $0,15 \mathrm{~ns}$ & $-0,38^{\star *}$ & $0,38 * *$ & $0,14 \mathrm{~ns}$ \\
\hline CE & & & & & 1,00 & $0,16 \mathrm{~ns}$ & $-0,40 * \star$ & $0,37 * \star$ & 0,26 * \\
\hline $\mathrm{pH}$ & & & & & & 1,00 & $-0,22$ ns & $0,20 \mathrm{~ns}$ & 0,12 ns \\
\hline$A R$ & & & & & & & 1,00 & $-0,97 \star \star$ & $-0,44^{\star \star}$ \\
\hline$S$ & & & & & & & & 1,00 & $0,21 \mathrm{~ns}$ \\
\hline$A G$ & & & & & & & & & 1,00 \\
\hline \multicolumn{10}{|c|}{ Área 2} \\
\hline Prof & $-0,70$ ** & $-0,63^{\star *}$ & $-0,84^{\star *}$ & $-0,91^{\star *}$ & $-0,56^{\star \star}$ & $-0,50$ ** & $0,47 * \star$ & $-0,58$ ** & $0,29 * *$ \\
\hline K & 1,00 & $0,44^{\star *}$ & $0,67^{* *}$ & $0,70^{\star *}$ & $0,61^{\star *}$ & $0,41^{\star *}$ & $-0,62^{\star *}$ & 0,60 ** & $0,28 * *$ \\
\hline $\mathrm{Na}$ & & 1,00 & $0,48 * *$ & $0,55^{\star *}$ & $0,22^{*}$ & $0,34 * *$ & 0,03 ns & $-0,14 \mathrm{~ns}$ & $0,39 * \star$ \\
\hline $\mathrm{Ca}$ & & & 1,00 & $0,96 * \star$ & $0,61 * *$ & $0,56 * *$ & $-0,54^{\star \star}$ & $0,67^{* *}$ & $-0,30 * *$ \\
\hline $\mathrm{Mg}$ & & & & 1,00 & $0,59 * *$ & 0,56 ** & $-0,56^{\star \star}$ & $0,66^{\star *}$ & $-0,20 \mathrm{~ns}$ \\
\hline $\mathrm{CE}$ & & & & & 1,00 & 0,24 ** & $-0,54^{* *}$ & $0,58 * *$ & $-0,01 \mathrm{~ns}$ \\
\hline $\mathrm{pH}$ & & & & & & 1,00 & $-0,38^{* *}$ & $0,40 * *$ & $0,05 \mathrm{~ns}$ \\
\hline$A R$ & & & & & & & 1,00 & $-0,97^{* *}$ & $-0,38 * *$ \\
\hline$S$ & & & & & & & & 1,00 & 0,13 ns \\
\hline$A G$ & & & & & & & & & 1,00 \\
\hline \multicolumn{10}{|c|}{ Variáveis } \\
\hline Prof & $-0,71^{* *}$ & $-0,44^{\star *}$ & $-0,87^{* \star}$ & $0,03 \mathrm{~ns}$ & $-0,43^{\star *}$ & $-0,79$ ** & $-0,83^{\star *}$ & $-0,80$ ** & $0,87^{* *}$ \\
\hline K & 1,00 & $0,40 \star \star$ & $0,78 \star \star$ & $-0,39 * \star$ & 0,60 ** & 0,66 ** & 0,64 ** & $0,68 * \star$ & $-0,70$ ** \\
\hline $\mathrm{Na}$ & & 1,00 & 0,46 ** & $-0,14$ ns & $0,29 * *$ & $0,39 * *$ & $0,35^{\star *}$ & 0,38 ** & 0,39 ** \\
\hline $\mathrm{Ca}$ & & & 1,00 & $-0,12$ ns & 0,57 ** & $0,84^{* *}$ & $0,79 * *$ & 0,77 ** & $-0,83 * *$ \\
\hline $\mathrm{Mg}$ & & & & 1,00 & $-0,36$ ** & $0,08 \mathrm{~ns}$ & $-0,41 * \star$ & $-0,53 * *$ & $0,49 * *$ \\
\hline CE & & & & & 1,00 & $0,40 * *$ & $0,55^{\star *}$ & $0,61 * *$ & $-0,61 * *$ \\
\hline $\mathrm{pH}$ & & & & & & 1,00 & $0,50 * *$ & $0,59 * *$ & $-0,57 * \star$ \\
\hline$A R$ & & & & & & & 1,00 & $0,78^{* *}$ & $-0,96^{\star *}$ \\
\hline$S$ & & & & & & & & 1,00 & $-0,93^{\star *}$ \\
\hline$A G$ & & & & & & & & & 1,00 \\
\hline \multicolumn{10}{|c|}{ Área 4} \\
\hline Prof & $-0,50$ ** & $-0,80^{* *}$ & $-0,45^{\star \star}$ & $0,09 \mathrm{~ns}$ & $0,49 * *$ & $-0,82^{* *}$ & $-0,60^{* *}$ & $-0,72^{\star *}$ & $0,76^{\star *}$ \\
\hline K & 1,00 & $0,57^{* *}$ & $-0,01 \mathrm{~ns}$ & $-0,19 \mathrm{~ns}$ & $-0,10 \mathrm{~ns}$ & $0,43^{\star *}$ & $0,33^{\star *}$ & 0,18 & $-0,34^{\star *}$ \\
\hline $\mathrm{Na}$ & & 1,00 & $0,10 \mathrm{~ns}$ & $-0,35^{\star \star}$ & $-0,19 \mathrm{~ns}$ & $0,72^{\star \star}$ & $0,47 * \star$ & $0,55^{\star \star}$ & $-0,60 * \star$ \\
\hline $\mathrm{Ca}$ & & & 1,00 & $0,73^{\star *}$ & $-0,32^{\star *}$ & $0,59 * *$ & $-0,02$ ns & $-0,16 \mathrm{~ns}$ & $0,07 \mathrm{~ns}$ \\
\hline $\mathrm{Mg}$ & & & & 1,00 & $-0,09$ ns & $0,18 \mathrm{~ns}$ & $-0,17$ ns & $-0,34^{\star \star}$ & 0,26 \\
\hline $\mathrm{CE}$ & & & & & 1,00 & $-0,43^{\star \star}$ & $-0,11 \mathrm{~ns}$ & $0,06 \mathrm{~ns}$ & $0,07 \mathrm{~ns}$ \\
\hline $\mathrm{pH}$ & & & & & & 1,00 & $0,40 * \star$ & 0,30 ** & $-0,45^{\star \star}$ \\
\hline$A R$ & & & & & & & 1,00 & $0,27^{*}$ & $-0,94^{\star *}$ \\
\hline$S$ & & & & & & & & 1,00 & $-0,58^{* *}$ \\
\hline$A G$ & & & & & & & & & 1,00 \\
\hline
\end{tabular}

* significativo a 5 \%; ** significativo a $1 \%$; ns - não significativo; Prof - profundidade; AR - areia; S - silte; AG - argila. 
Potássio $\left(\mathrm{cmol}_{\mathrm{c}} \mathrm{dm}^{-3}\right)$

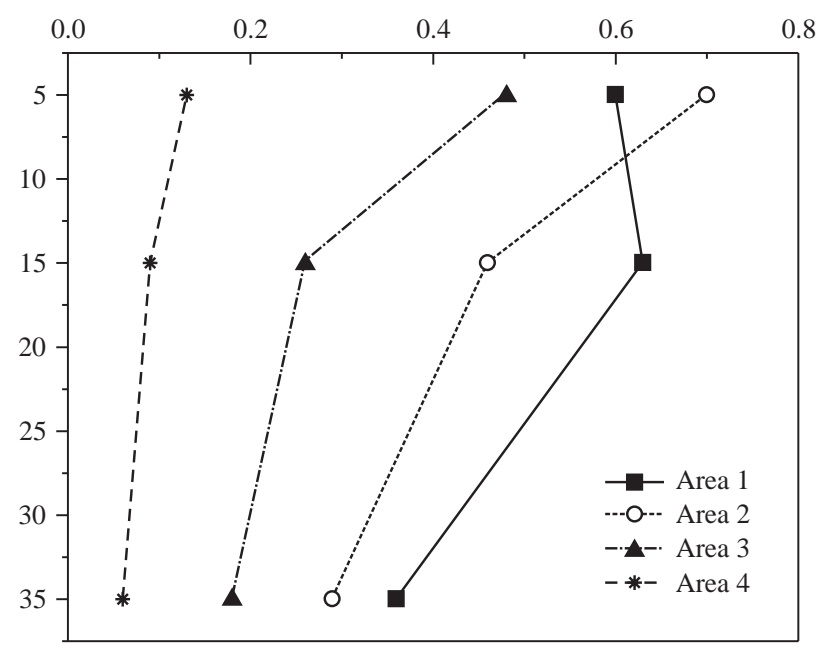

Cálcio $\left(\mathrm{cmol}_{\mathrm{c}} \mathrm{dm}^{-3}\right)$

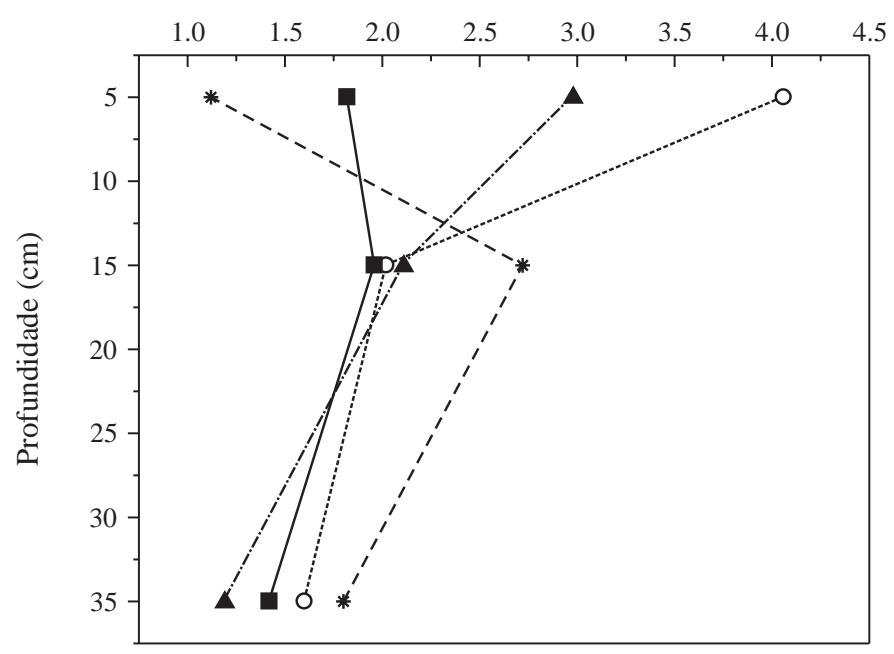

$\mathrm{pH}$

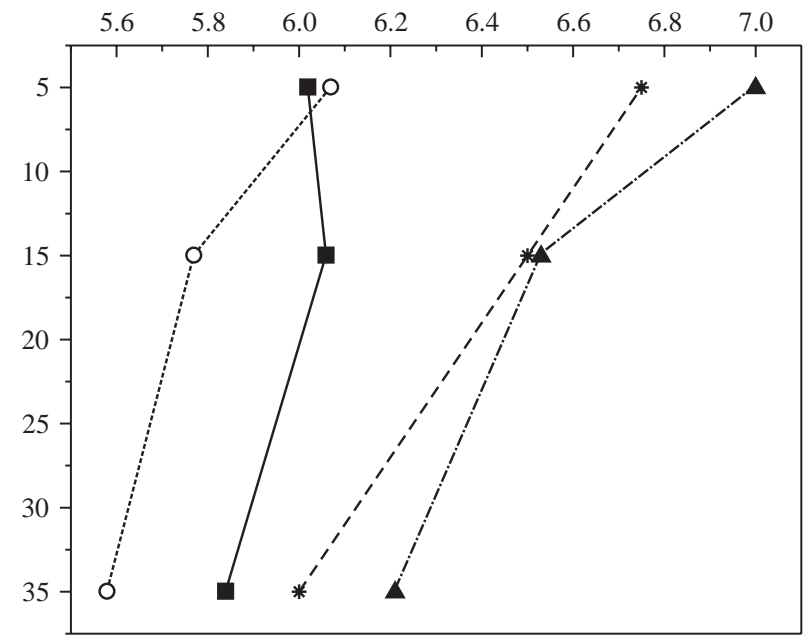

Sódio $\left(\mathrm{cmol}_{\mathrm{c}} \mathrm{dm}^{-3}\right)$

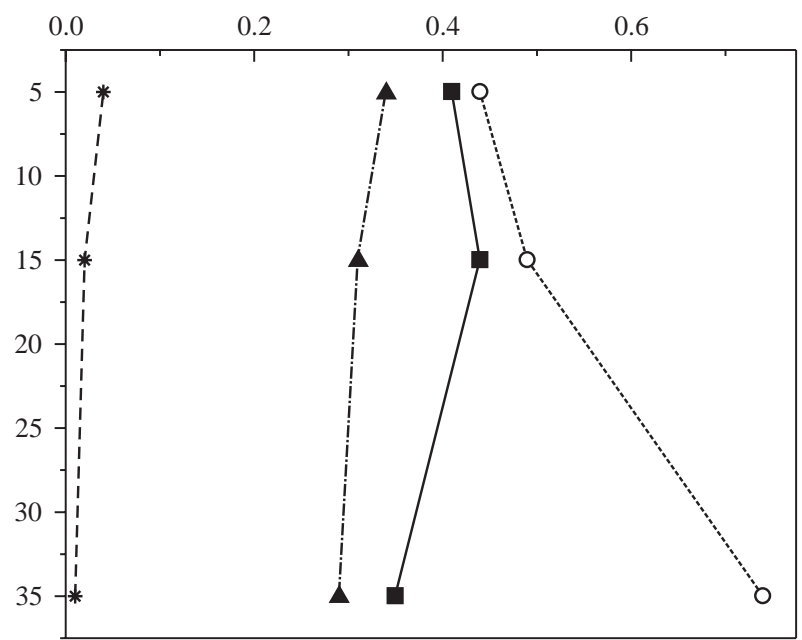

Magnésio $\left(\mathrm{cmol}_{\mathrm{c}} \mathrm{dm}^{-3}\right)$

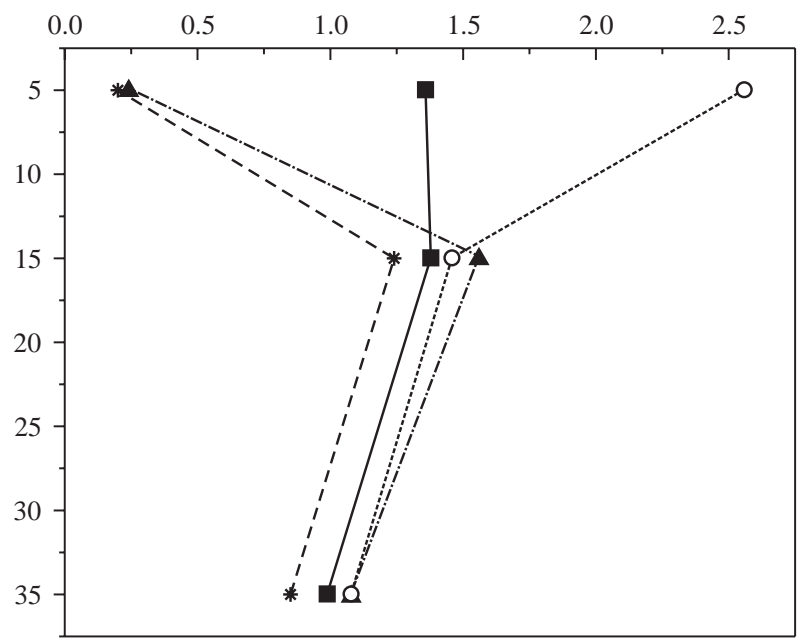

$\mathrm{CE}_{\mathrm{es}}\left(\mathrm{dS} \mathrm{m} \mathrm{m}^{-1}\right)$

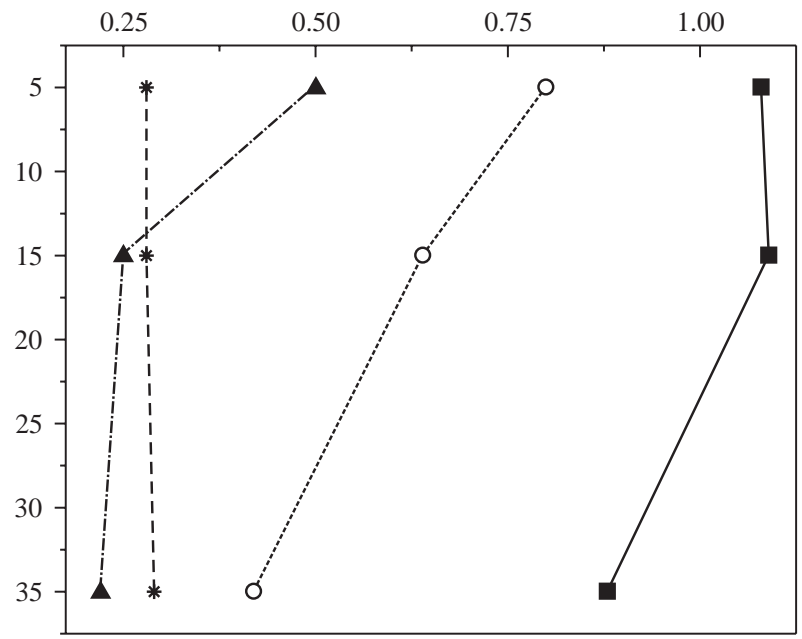

Figura 2. Valores médios das variáveis avaliadas nas profundidades 0 - 10, 10 - 20 e 20 - $40 \mathrm{~cm}$ (Área 1 = 3 anos de aplicação de vinhaça, Área 2 = 7 anos, Área $3=15$ anos e Área 4 sem aplicação de vinhaça)

Este resultado deve estar associado à aplicação de vinhaça que, além da elevada concentração de K, apresenta outros elementos, como Ca, Mg e Na, em sua composição, oca- sionando incremento no solo.

Paula et al. (1999) encontraram acréscimos de Ca e Mg na camada de 0-20 cm, enquanto na de $20-40 \mathrm{~cm}$ não houve al- 
teração. Resultados semelhantes foram observados por Brito et al. (2005), cujos maiores teores de K trocável em Espodossolo ocorreram no horizonte superficial $(0-15 \mathrm{~cm})$ do perfil do solo; entretanto, Camargo et al. (1987) observaram aumento dos cátions trocáveis em quase todas as profundidades devido à quantidade desses elementos adicionada pela vinhaça.

Os valores de $\mathrm{Mg}$ se correlacionaram negativamente com a profundidade nas Áreas 1 e 2, comportamento semelhante ao do $\mathrm{Ca}$, que ficou retido nas camadas superficiais do solo (Figura 2). O Ca correlacionou-se significativamente $(\mathrm{P} \leq 01)$ com o Mg em quase todas as áreas, com exceção da Área 3 (Tabela 2). O solo dessas áreas foi corrigido com 2 toneladas por hectare de calcário dolomítico e, 'a medida em que se dissolve, libera Ca e Mg que são adsorvidos nas cargas negativa dos colóides, aumentando assim o teor desses cátions na micela e, consequentemente, na solução do solo, favorecendo o acréscimo de Ca e Mg, além da vinhaça aplicada (Maia \& Ribeiro, 2004).

Os valores de $\mathrm{CE}_{\mathrm{es}}$ se correlacionaram com as variáveis Ca, Mg, Na e K nas Áreas 1, 2 e 3, as quais foram fertirrigadas com vinhaça ao longo dos anos (Tabela 2). Na Área 4 houve correlação significativa entre $\mathrm{CE}_{\mathrm{es}}$ e Ca e, também, com a profundidade (Figura 2); contudo, não se correlacionou com o K e Na, provavelmente porque a Área 4 apresenta baixos teores desses elementos, uma vez que nunca foi aplicada vinhaça. $O$ valor médio de $C_{\text {es }}$ na camada de 10-20 cm foi maior em relação às camadas 0-10 e 20-40 cm, indicando leve lixiviação do $\mathrm{Ca}$, existente em maior proporção em virtude da aplicação a lanço, de calcário, ocorrida na Área. De modo geral, o incremento de Ca, Mg e K resultou no aumento da $\mathrm{CE}_{\mathrm{es}}$ que representa a quantidade de cátions solúveis no extrato de saturação do solo. Em áreas fertirrigadas com vinhaça estudadas por Camargo et al. (1987), a $\mathrm{CE}_{\mathrm{es}}$ atingiu, na camada de $0-10 \mathrm{~cm}, 4,9 \mathrm{dS} \mathrm{m}^{-1}$ em uma das amostragens mas não houve diferença nos resultados para os diversos tratamentos nem para a profundidade.

Quanto ao pH, observou-se correlação negativa com a profundidade no solo das Áreas 2, 3 e 4 (Tabela 2), evidenciando redução com o aumento da profundidade (Figura 2). Concernente às correlações entre $\mathrm{pH}$ e as outras variáveis, ocorreu correlação positiva com o K na Área 1; K, Na, Ca e Mg na Área 2; K, Na e Ca nas Áreas 3 e 4 (Tabela 2). As camadas mais profundas do solo geralmente apresentam maior acidez em relação às camadas superficiais devido à aplicação de corretivos (calcário) e adubações que favorecem o aumento do pH do solo (Maia \& Ribeiro, 2004). Por outro lado, Nunes et al. (1981) relatam que o aumento do $\mathrm{pH}$ do solo é resultante do aumento de bases trocáveis, principalmente o K, incorporadas pela aplicação de vinhaça que, em geral, ocorrem nas camadas mais superficiais. Brito et al. (2005) verificou aumento do $\mathrm{pH}$ em todos os solos estudados e com as doses de vinhaça de 350 e $700 \mathrm{~m}^{3} \mathrm{ha}^{-1}$.

Nas Áreas 1 e 2 ocorreu correlação negativa entre areia e silte, constatando-se aumento de areia e redução de silte com a profundidade (Tabela 2); em relação às Áreas 3 e 4, areia e argila se correlacionaram negativamente com a profundidade $(P \leq 0,01)$ (Tabela 2$)$ evidenciando leve redução na quantidade de areia e, consequentemente, acréscimo na quan- tidade de argila com o aumento da profundidade (Figura 2); já na Área 3 a correlação foi positiva entre areia e silte (Tabela 2), redução de areia e silte simultaneamente com a profundidade (Figura 2).

Os elementos $\mathrm{Ca}$ e $\mathrm{Mg}$ se correlacionaram negativamente com os teores de areia e positivamente com os teores de silte na Área 2 (Tabela 2). À proporção em que aumentou a quantidade de areia em profundidade, verificou-se redução do Ca e Mg. Ribeiro et al. (1983), em experimento para verificar a dispersão de argila utilizando vinhaças de diferentes composições, concluíram que a vinhaça com maior concentração de $\mathrm{K}$, Ca e Mg não apresentou efeito dispersante da argila. Freire \& Aguiar (1993), quando incorporaram vinhaça concentrada em Latossolo de textura média e argilosa verificaram aumento nos teores de argila, silte e areia média nos solos, em relação aos tratamentos que não receberam vinhaça.

Houve correlação negativa entre o teor de $\mathrm{K}$ e a quantidade de areia $(\mathrm{P} \leq 0,01)$ na Área 2 (Tabela 2) indicando a não lixiviação no perfil como pode ser observado na Figura 2. Era de se esperar lixiviação do K no perfil do solo devido à alta mobilidade deste elemento, além da permeabilidade do solo. Para avaliar a qualidade de solos do ponto de vista ambiental, a não lixiviação é fator importante, haja vista que minimiza a elevação de sais nas águas do lençol freático.

\section{CONCLUSÕES}

1. As alterações físico-químicas que ocorreram nos solos das diferentes áreas foram influenciadas pela aplicação de vinhaça, corretivo, além das diferentes características físicas dos solos.

2. Houve aumento de potássio em todas as profundidades dos solos correspondentes às áreas fertirrigadas com vinhaça, independente dos períodos de aplicação.

3. A fertirrigação com vinhaça ao longo dos anos não alterou o $\mathrm{pH}$ dos solos.

\section{LITERATURA CITADA}

Brasil. Grupo de Trabalho Interministerial do Setor Sucroalcooleiro da Região Nordeste (Decreto de 21 de outubro de 2004). Casa Civil da Presidência da República, 2005, 100p.

Brito, F. L.; Rolim, M. M.; Pedrosa, E. M. R. Teores de potássio e sódio no lixiviado e em solos após a aplicação de vinhaça. Revista Brasileira de Engenharia Agrícola e Ambiental, v.9 (Suplemento), p.52-56, 2005.

Camargo, O. A.; Valadares, J. M. A. S.; Berton, R. S.; Teófilo Sobrinho, J.; Menk, J. R. F. Alteração de características químicas de um Latossolo Vermelho-Escuro distrófico pela aplicação de vinhaça. Campinas: Instituto Agronômico, 1987. 23p. Boletim n.9

Camargo, O. A.; Valadares, J. M. A. S.; Geraldi, R. N. Características químicas e físicas de solo que recebeu vinhaça por longo tempo. Campinas: Instituto Agronômico, 1983. 30p. Boletim n.76 
Cambuim, F. A. A ação da vinhaça sobre a retenção de umidade, pH, acidez total, acumulação e lixiviação de nutrientes, em solo arenoso. Recife: UFRPE, 1983. 133p. Dissertação Mestrado

Corá, J. E.; Araújo, A. V.; Pereira, G. T.; Beraldo, J. M. G. Variabilidade espacial de atributos do solo para adoção do sistema de agricultura de precisão na cultura de cana-de-açúcar. Revista Brasileira de Ciência do Solo, v.28, p.1013-1021, 2004.

EMBRAPA - Empresa Brasileira de Pesquisa Agropecuária. Manual de métodos de análises de solo. 2.ed. Rio de Janeiro: EMBRAPA, 1997. 212p.

EMBRAPA - Empresa Brasileira de Pesquisa Agropecuária. Centro Nacional de Pesquisa de Solos. Sistema brasileiro de classificação de solos. Rio de Janeiro: EMBRAPA, 2006. 306p.

Feigin, A.; Ravina, I.; Shalhevet, J. Irrigation with treated sewage effluent: management for environmental protection. Berlin: Springer-Verlag, 1991. 224p.

Freire, W. J.; Aguiar, M. A. Incorporação de vinhaça concentrada em dois solos distintos: Características químicas, físicas e mecânicas da mistura obtida. Engenharia Agrícola, v.13, p.85-96, 1993.

Freire, W. J.; Cortêz, L. A. B. Vinhaça de cana-de-açúcar. Guaíba: Agropecuária, 2000. 203p.

Glória, N. A. Emprego da vinhaça para fertilização. Piracicaba: Codistil, 1976. 31p.
Maia, J. L. T.; Ribeiro, M. R. Cultivo contínuo da cana-de-açúcar e modificações químicas de um Argissolo Amarelo fragipânico. Pesquisa Agropecuária Brasileira, v.39, n.11, p.1127-1132, 2004.

Medeiros, S. C. L.; Ribeiro, S. R.; Coneglian, C. M. R.; Barros, R. M.; Brito, N. N.; Dragoni Sobrinho, G.; Tonso, S.; Pelegrini, R. Impactos da agroindústria canavieira sobre o meio ambiente. In: Fórum de Estudos Contábeis, 3, 2003, Rio Claro, Anais... Rio Claro: UNICAMP, 2003. CD Rom.

Nunes, M. R.; Velloso, A. C. X.; Leal, J. R. Efeito da vinhaça nos cátions trocáveis e outros elementos químicos do solo. Pesquisa Agropecuária Brasileira, v.16, n.2, p.171-176, 1981.

Paula, M. B.; Holanda, F. S. R.; Mesquita, H. A.; Carvalho, V. D. Uso da vinhaça no abacaxizeiro em solo de baixo potencial de produção. Pesquisa Agropecuária Brasileira, v.7, p.1217-1222, 1999.

Ribeiro, A. C.; Novais, R. F.; Bahia Filho, A. F. C. Efeitos da vinhaça sobre a dispersão de argila de amostras de Latossolos. Revista Ceres, v.30, n.167, p.12-18. 1983.

SAS Institute, Inc. SAS/STAT User's Guide, Version 6, 4.ed. v.1, Cary: SAS Institute, 1989. 956p.

Sengik, E.; Ribeiro, A. C.; Condé, A. R. Efeito da vinhaça em algumas propriedades de amostras de dois solos de Viçosa, MG. Revista Brasileira de Ciência do Solo, v.12, p.11-15, 1988.

UNICA - União dos Produtores de Cana-de-Açúcar. http:// www.unica.com.br/pages/ agroindustria_alta.asp. 10 Fev. 2007. 